\title{
GI-MS47-05 | Women in A Historical French LABORATORY OF Crystallography
}

Cabaret, Delphine (Sorbonne Université, Paris, FRA); Brouder, Christian (Sorbonne Université, CNRS, Paris, FRA)

The Chair of Mineralogy of The Sorbonne, created in 1809 for René-Just Haüy, evolved to the present Institute of Mineralogy, Materials Physics and Cosmochemistry (IMPMC) of Sorbonne Université. Brilliant women crystallographers have been working or still work in this laboratory, which also is the headquarter of the two French societies of crystallography (AFC and SFMC). The research activities of these women scientists range from experimental to theoretical diffraction, and concern the exploration of extraterrestrial samples as well as the development of synchrotron beamlines.

In this talk, we will examine the careers of some women researchers of our laboratory, who had striking contributions in the French crystallography from the 60s to nowadays. This presentation will be set in a more general context of women crystallographers in Paris in the twentieth century. 